\title{
O RECONHECIMENTO DE CRIANÇA E ADOLESCENTE COMO SUJEITOS DE DIREITOS E A ATUAÇÃO DO ESTADO BRASILEIRO AO LONGO DO TEMPO PARA EFETIVÁ-LOS

\author{
THE RECOCNITION OF CHILDREND AND ADOLESCENTS AS THE AIM OF \\ FUNDAMENTAL RIGHTS AND THE STATES PERFORMANCE TO FULLFIL \\ THEM
}

${ }^{1}$ Ana Carolina Figueiro Longo

\section{RESUMO}

O presente trabalho busca discutir o processo histórico que motivou a mudança de paradigma para a efetivação dos direitos das crianças e adolescentes. O texto descreve o conteúdo normativo empregado na efetivação de direitos para constatar que esta parcela da população somente foi reconhecida como sujeito de direitos a partir da promulgação da Constituição brasileira de 1988. Antes desta data, crianças e adolescentes, se não protegidas em sua unidade familiar, eram objeto de atenção do Estado tão somente sob o aspecto sanitário e comportamental, não para protegê-los, mas para assegurar a tranqüilidade da sociedade. A partir de 1988, contudo, há uma mudança significativa de paradigma, permitindo que o foco da atenção estatal seja a própria criança e adolescente, buscando sua proteção integral de modo a viabilizar seu pleno desenvolvimento.

Palavras-chave: Infância e juventude, Proteção constitucional, Mudança de paradigma, Efetivação de direitos fundamentais

\begin{abstract}
This paper discusses the historical process that led to the paradigm shift on the realization of children and adolescents rights. The text describes the normative content used in enforcing rights to realize that this population was only recognized as a subject of rights after the promulgation of the Brazilian Constitution of 1988. Before this date, children and adolescents, if not protected in their family, were the subject of government attention only on the health and criminal aspects, but not to protect them, but to ensure the tranquility of society. Since 1988, however, there is a significant paradigm shift, allowing the state attention $\mathrm{s}$ focus throughout child and teenagers, seeking to their full protection in order to enable their full development as human being.
\end{abstract}

Keywords: Childhood and youth, Constitutional protection, Paradigm shift, Execution of fundamental rights

\footnotetext{
${ }^{1}$ Mestre em Direito Constitucional pelo Instituto Brasiliense de Direito Público - IDP, Brasília - DF (Brasil). Professora do Centro Universitário de Brasília - UniCEUB. Brasília - DF (Brasil).

E-mail: ana@carolinalongo.com.br
} 


\title{
INTRODUÇÃO
}

Recente é o reconhecimento de crianças e adolescentes como sujeitos de direito pelo ordenamento jurídico brasileiro. Apenas a partir dos anos de 1988 é que se pode identificar, a positivação de direitos direta e exclusivamente dedicados a esta parcela da população.

Do texto da Constituição Brasileira de 1988 consta, pois, proteção ampla à infância e juventude, com prioridade absoluta, nos termos do art. 227:

\begin{abstract}
Art. 227. É dever da família, da sociedade e do Estado assegurar à criança, ao adolescente e ao jovem, com absoluta prioridade, o direito à vida, à saúde, à alimentação, à educação, ao lazer, à profissionalização, à cultura, à dignidade, ao respeito, à liberdade e à convivência familiar e comunitária, além de colocá-los a salvo de toda forma de negligência, discriminação, exploração, violência, crueldade e opressão.
\end{abstract}

Os demais artigos do Capítulo VII da Constituição complementam a lista de direitos fundamentais especialmente direcionados à parcela da população que conta com menos de 18 anos de idade, proteção que se especifica na legislação infraconstitucional regulamentadora.

É relevante destacar que apenas a partir da promulgação da constituição vigente que se assegurou, na condição de direito subjetivo, a proteção da infância e juventude. Foi criado, pois, um micro-sistema de atenção especial, que assegura a proteção integral.

Esta é uma mudança de perspectiva importante, que viabiliza a mobilização das ações estatais para as condições especiais desta população de pessoas em desenvolvimento. Veja-se que, antes, crianças e adolescentes que não estavam integrados na proteção de um núcleo familiar eram vistos como um problema social e a política estatal estabelecida se voltava apenas para a proteção da sociedade.

Positivado um extenso rol de direitos fundamentais destinados a essa parcela da população a partir de 1988, elas passaram a ser reconhecidos como sujeitos de direitos e, portanto, objetos de políticas públicas especificamente voltadas para a proteção de seus interesses. Esta compreensão é uma conquista recente, visto que os primeiros atos normativos brasileiros que cuidavam da infância e juventude ocupavam-se ora com uma concepção assistencialista aos "desamparados", ora com o aspecto criminal de seu comportamento.

Este trabalho volta sua atenção para as diversas modificações da legislação que justificaram a atribuição de responsabilidade solidária ao Estado, à sociedade e à família, para assegurar à criança e ao adolescente o gozo, com absoluta prioridade de seus direitos 
fundamentais. E, em especial, volta o olhar para aqueles que não estão inseridos em um núcleo familiar, para quem também se deve garantir a plenitude de seus direitos.

Buscou-se, portanto, compreender o movimento histórico que justificou essa mudança de perspectiva, reconhecendo como centro das atenções a criança e o adolescente e não mais a sociedade.

De modo a demonstrar a mudança do objeto na estrutura normativa voltada para a infância e juventude, é possível dividir a legislação da infância e juventude em cinco períodos distintos: a fase pré-republicana, na qual preponderava a intervenção religiosa a amparar os jovens sem família; a primeira república, cuja ordem legislativa se dirigia à assistência higiênica ou científica; fase da assistência social, influenciada pela positivação de direitos sociais, a partir da década de 1930 até a criação da FEBEM, ocorrida em 1964; uma fase punitiva, com foco em conter menores repressores; e finalmente, um momento de proteção integral, inaugurado com a Constituição de 1988.

\section{PERÍODO PRÉ-REPUBLICANO: ASSISTÊNCIA RELIGIOSA}

A Constituição do Império, nos trinta e cinco incisos do art. 179, que dispunha acerca dos direitos e garantias fundamentais, em nada tratou da proteção da infância, juventude e da família. Esta era uma esfera de competências exclusivamente exercida no âmbito de cada núcleo familiar, e apesar de prevista na legislação municipal, era efetivamente exercida pela sociedade civil, mediante convênios. Até porque o império português no Brasil se estabeleceu com o fito principal de assegurar os interesses e privilégios das classes dominantes (BOSCHI s.d., 25-41)

Aos órfãos e desamparados cabia a caridade religiosa ou de grupos filantrópicos, cite-se, por exemplo, a Casa da Roda, instituição de origem católica que oferecia alimento e amparo para as crianças sem família. Vale ressaltar que os governos locais inicialmente detinham o controle da atividade de controle de órfãos e expostos, mas paulatinamente transferiram aos particulares a tarefa.

Conforme dispõem os arts. 69 e 70 da Lei dos Municípios de 1828, lei geral que distribuía competências para as Câmaras Municipais de todo o País, que caberia a estas casas legislativas, estabelecer convênios com instituições privadas para zelar pelas crianças desamparadas, então qualificadas como "expostos": 
Art. 69. Cuidaráõ no estabelecimento e conservação das casas de caridade, para que se criem expostos, se curem os doentes necessitados, e se vaccinem todos os meninos do disctricto, e adultos que não o tiverem sido, tendo Medico ou Cirurgião de partido.

Art. 70. Terão inspecção sobre as escolas de primeiras lettras, educação e destino dos órphãos pobres, em cujo numero entrarão os expostos; e quando estes estabelecimentos, e os de caridade, de que tracta o art. 69, se achem por lei, ou de facto, encarregados em alguma cidade ou villa a outras auctoridades individuaes ou colletivas, as Câmaras auxiliaráõ sempre quanto estiver da sua parte para a prosperidade e augumento dos sobredictos estabelecimentos. (LAXE, João Baptista Cortines. 1885. Regimento das Câmaras Municipaes, ou, Lei de 1. de Outubro de 1828 : annotada com as leis, decretos, regulamentos e avisos que revogão, ou alterão suas disposições e explicão sua doutrina : precedida de uma introdução historica, e seguida de sete appensos. [Online] 1885. Livro Raro. http://www2.senado.gov.br/bdsf/item/id/227296.)

Diante desta regulamentação, as Câmaras Municipais estabeleciam convênios com as instituições privadas, em especial as Santas Casas de Misericórdia, para que zelassem pela administração das Rodas dos Expostos (MARCÍLIO 1998)

As rodas eram instrumentos comumente instalados em instituições de caráter religioso, em especial nas Santas Casas, e consistiam em dispositivo com a seguinte estrutura:

forma cilíndrica e com uma divisória no meio, esse dispositivo era fixado no muro ou na janela da instituição. No tabuleiro inferior da parte externa, o expositor colocava a criança que enjeitava, girava a Roda e puxava um cordão com uma sineta para avisar à vigilante - ou Rodeira - que um bebê acabara de ser abandonado, retirando-se furtivamente do local, sem ser reconhecido. (MARCÍLIO 1998)

Sob o aval da Coroa Portuguesa, quando, por uma questão de honra cristã, ou por absoluta impossibilidade de manter as crianças, mães deixavam seus filhos para que aquelas instituições filantrópicas pudessem cuidar e educá-las.

Outra situação verificável durante o Império é aquela em que as crianças eram deixadas nas soleiras das portas de pessoas mais abastadas, e, por caridade, aquelas crianças eram integradas à nova família ${ }^{1}$. E esta era uma prática comum e incentivada no âmbito social.

O cuidado dos órfãos e expostos poderia ainda ser feito por amas de leite: mulheres que recebiam salário para que cuidassem de filhos de outras. O pagamento se daria mensalmente mediante a apresentação das crianças às Santas Casas para exames de saúde.

1 "No Brasil o costume de criar um filho alheio nas famílias foi amplamente difundido, aceito e valorizado. Bastava verificar que em Mariana, em 57 anos (de 1779 a 1833), foram expostas em portas de casas de famílias 983 crianças. Destas, somente 36 não ficaram com as famílias em cujas portas foram deixadas $(3,6 \%)$. Não estaria aí uma prova significativa de que praticamente todos encaravam como dever intransferível o acolhimento do bebê encontrado na soleira de casa. Seria o ato de recolher e criar um recém-nascido abandonado um ato de caridade, compaixão, de piedade cristã? [...] Tal atitude, porém, não é simplesmente explicada pela via da religião. Em uma sociedade escravista (não-assalariada), os expostos incorporados a uma família poderiam representar um complemento ideal de mãode-obra gratuita. Por isso, criar um exposto poderia trazer vantagens econômicas; apenas com o ônus da criação - que, em alguns casos, recebia ajuda pecuniária da Câmara local ou da Roda dos Expostos - o 'criador' ou a ama-de-leite teriam mão-de-obra suplementar, e gratuita, mais eficiente do que a do escravo, porque livre e ligada a laços de fidelidade, de afeição e de reconhecimento" (MARCílIO, Maria Luiza. História Social da Criança Abandonada. São Paulo: Editora Hucitec, 1998) 
O abandono de crianças para as Santas Casas e demais instituições de acolhimento representava a solução de dois problemas para as mães, o primeiro era a desonra de uma gravidez fora do casamento, e também uma forma de as mulheres obterem sustento por meio da amamentação de outras crianças (TRINDADE 1999).

A atividade estava, inclusive, prevista nas Ordenações Filipinas, Livro 1 Tit. 88: Dos Juízes dos Órfãos, Título LXXXVIII:

Criação.

10. E se alguns Orfãos, nascidos de legítimo matrimonio, ficarem em tão pequena idade, que hajam mister criação, dal-os-hão a criar à suas mães, se as tiverem, em quanto se ellas não casarem. A qual criação serão obrigadas fazer até os Órfãos haverem três annos cumpridos: e isto de leito somente, sem por isso levar cousa alguma; e todo o AL lhes será dado dos bens dos ditos órfãos, conforme ao que na cidade, Villa ou lugar, se costuma dar às Amas por criação de meninos. E esta criação se pagará até o tempo, que os órfãos sejam em idade em que possam merecer alguma cousa por seu serviço. Porém, se alguma mai for de tal qualidade e condição, que não deva com razão criar seus filhos ao peito, ou por algum impedimento os não possa criar, será o órfão dado à Ama, que o crie assi de leite, como de toda a outra criação, que lhe for necessária, à usta dos bens dos distos Orfãos. E se não tiverem bens, per que se possa pagar sua criação, suas mais serão constrangidas que os criem de graça de toda criação, até serem de idade em que possam merecer soldada (Livro I, t. $67, \S 9^{\circ}$ )

11. Porém, se as crianças, que não forem de legítimo matrimônio, forem filhos de alguns homens casados, ou de solteiros, primeiro serão constrangidos seus pais, que os criem, e não tendo elles por onde os criar, se

criarão às custas da mais. E não tendo elles nem ellas por onde os criar, sejam requeridos seus parentes, que os mandem criar. E não o querendo fazer, ou sendo filhos de Religiosos, ou de mulheres casadas, os mandarão criar às custas dos Hospitaes, ou Albergarias, que houver na cidade, Villa ou lugar, se tiver bens ordenados para criação dos engeitados: de modo que as crianças não morram por falta de criação. Em ao havendo hi taes hospitaes e Albergarias, se criação à custa das rendas do Concelho. E não tendo o Conselho rendas, per que se possam criar, os Officaes da Camera lançarão fintas pelas pessoas, que nas fintas e encarregos do Conselho hão de pagar (Ordenações Filipinas, Livro 1, título 67, § 10).

Os gastos designados para a municipalidade para o cuidado com os órfãos era muito elevado, o que justifica que, com base na Lei dos Municípios, que a atividade fosse relegada cada vez mais aos particulares.

A estrutura de amparo focada na presença de Santas Casas de Misericórdia, amas de leite assalariadas e pouca intervenção do Estado no sentido de elaboração de políticas pública específicas, perdurou até a proclamação da República.

Posteriormente, o texto das Ordenações Filipinas determina aos Juízes dos órgãos o dever de zelar por seu bem estar e cuidado: 
3. E o Juiz dos Órgãos deve com grande diligência e cuidado saber quantos Órfãos há na cidade, Villa ou lugar, em que he Juiz, a fazel-os todos screver em hum livro ao Scrivão desse officio, declarando o nome de cada Órgão, e cujo filho He, e de que idade, e onde vive, e com quem, e quem He seu Tutor e Curador. E deve saber quantos bens móveis e de raiz, e quem os traz, e se andam bem aproveitados, danificados, ou perdidos, e por cuja culpa e negligência, para os poder fazer aproveitar e arrecadar. E assi deve fazer pagar aos Órfãos toda a perda e dano, quem em seus bens receberam, per aquelles que nisso achar negligentes, ou culpados. É o Juiz, que assi não cumprir, pagará os ditos Órfãos toda a perda e dano que por isso receberem (Portugal s.d.).

No final do período imperial a relação entre Estado e a Igreja passou por estremecimentos, o que gerou modificações em relação à atuação das Santas Casas de Misericórdia no amparo de crianças sem família.

Naquele momento histórico, as Rodas e as Santas Casas acolhiam as crianças até que completassem 7 (sete) anos, depois do que, as crianças que não haviam sido acolhidas por famílias ou destinadas ao trabalho ${ }^{2}$, eram deixadas na rua, à sua própria sorte. (FAUSTO 2001)

O número de crianças crescente nas ruas passou a gerar um problema social, sendo necessário que o Estado lhe voltasse os olhos, para prover meios de sua subsistência e retirá- las das ruas (MARCÍlLIO 1998). Vale destacar que as ações não se destinavam especificamente para políticas públicas de proteção da infância, mas consistiam em um instrumento de proteção da sociedade contra a situação de indigência que aquelas crianças estavam submetidas. O simples fato de as autoridades públicas retirarem estas crianças das ruas não é sinônimo de política pública voltada para a infância.

\section{ASSISTÊNCIA HIGIÊNICA OU CIENTÍFICA}

A partir do final do século XIX e início do século XX, o Estado passou a exercer uma política higiênica sobre as cidades, numa sociedade cada vez mais urbanizada ${ }^{3}$.

\footnotetext{
2 Nesta época era comum o anúncio de indústrias contratando crianças a partir de 7 anos de idade.

3 Vale destacar a famosa Revolta da Vacina, contra as políticas instituídas pelo Governo do Rio de Janeiro que pretendia vacinar compulsoriamente toda a população contra varíola, além de uma série de intervenções urbanas para minimizar o acúmulo de pessoas em cortiços sem condições de higiene e saneamento (EVCENKO, Nicolau, A Revolta da Vacina, São Paulo: Cosac Naify, 2010)
} 
Até porque, o número de crianças abandonadas, e os números alarmantes de mortalidade infantil aumentavam cada vez mais, fazendo ver que a solução de recolhimento das crianças não era uma atitude eficiente para o problema. "Nessa nova prática se consolida cada vez mais uma nova noção: "educar pelo trabalho e para o trabalho", noção essa em pleno acordo com a consolidação do novo tempo, o tempo do trabalho industrial" (TRINDADE 1999).

Os meninos abandonados formavam uma força de trabalho expressiva, mas as meninas abandonadas representavam um peso social, visto que somente teriam algum futuro se obtivessem um casamento, e para isso seria necessário que alguém por elas pagasse o dote. Por esta razão, acabavam internadas em asilos ou seminários.

Entre as primeiras instituições destinadas aos abandonados ou delinquentes, constavam o Seminário de Educandas da Glória, o Seminário de Educandos de Sant'Ana, o Asilo de Mendicidade da Corte, o Asilo de Meninos Desvalidos, a Escola Correcional "Quinze de Novembro" e o Instituo Disciplinar, fundado em 1903, a partir de uma exigência do Código Penal instituído em 1890. (RODRIGUES e LIMA 2014).

Além disso, é possível verificar uma crescente preocupação com crianças e adolescentes em situação de delinquência. Novamente, a legislação e intervenção estatal não têm o cunho de proteger este jovem desviado, e reintegrá-lo à uma situação social adequada $\mathrm{A}$ preocupação era proteger a sociedade vítima desta violência infanto-juvenil.

O Código Penal de 1890 considerava que crianças com mais de 9 (nove) anos, com discernimento, já poderiam ser punidas criminalmente:

Art. 27. Não são criminosos:

$\S 1^{\circ}$ Os menores de 9 annos completos;

$\S 2^{\circ}$ Os maiores de 9 e menores de 14 , que obrarem sem discernimento;

$\S 3^{\circ}$ Os que por imbecilidade nativa, ou enfraquecimento senil, forem absolutamenteincapazes de imputação;

$\S 4^{\circ}$ Os que se acharem em estado de completa privação de sentidos e de intelligenciano acto de commetter o crime;

$\S 5^{\circ}$ Os que forem impellidos a commetter o crime por violencia physica irresistivel, ouameaças acompanhadas de perigo actual;

$\S 6^{\circ}$ Os que commetterem o crime casualmente, no exercicio ou pratica de qualquer acto licito, feito com attenção ordinaria;

$\S 7^{\circ}$ Os surdos-mudos de nascimento, que não tiverem recebido educação neminstrucção, salvo provando-se que obraram com discernimento.

Da leitura da lei, verifica-se que as crianças com menos de 9 (nove) anos eram inimputáveis, todavia, as que possuíam idades entre 9 e 14 anos poderiam ser julgadas, como se adultos fossem, desde que o magistrado - ainda que por critérios subjetivos - entendesse 
que já podiam se determinar e ter consciência de seus atos. Para acolher estes jovens infratores foram criados diversos reformatórios, cujo formato era o de pequenas prisões.

\section{FASE DA ASSISTÊNCIA SOCIAL}

Nos anos de 1930 se inicia uma nova fase evolutiva da proteção da criança e adolescente no Brasil. Há um significativo aumento da preocupação com a infância pelo Governo Federal, que estrutura o Departamento Nacional da Criança e o Serviço de Assistência a Menores, cujo objetivo é pensar nacionalmente em políticas públicas e orientar as práticas de assistência social, tanto na esfera pública, como privada.

Vale destacar que o Código de Menores de 1926 tinha com objetivo, dirigido diretamente ao Governo, de consolidar a legislação de assistência ao menor, de modo a assegurar as "demais medidas necessarias á guarda, tutela, vigilancia, educação, preservação e reforma dos abandonados ou delinquentes, dando redacção harmonica e adequada a essa consolidação" (BRASIL, 1926).

Há uma mudança no modo de agir do Estado que se assume responsável pela guarda, tutela, vigilância, educação e preservação de crianças. Entretanto, a legislação ainda se restringe a crianças abandonadas ou delinquentes, e não à proteção da infância de maneira geral.

Há um aumento da proteção estatal com o cuidado com as crianças sem famílias, especialmente em razão da regulamentação das atividades de guarda e abrigamento, determinando-se, inclusive o dever da autoridade responsável por visitas "as escolas, officinas e qualquer outro logar onde se achem menores, e proceder a investigações” (art. 73). Nesta etapa se verifica uma aproximação da atividade estatal com a política pública de efetivação de direitos fundamentais vigente.

O Código de Menores estabelece regramentos mínimos para a custódia de crianças, mas ainda possui critérios bastante subjetivos para a retirada destes dos reformatórios:

Art. 52. O menor internado em escola de reforma poderá obter liberdade vigiada, concorrendo as seguintes condições:
a) si tiver 16 annos completos;
b) si houver cumprido, pelo menos, o minimo legal do tempo de internação c) si não houver praticado outra infracção;
d) si fôr considerado moralmente regenerado
e) si estiver apto a ganhar honradamente a vida, ou tiver meios de subsistencia, ou quem lh'os ministre


f) si a pessoa, ou familia, em cuja companhia tenha de viver, fôr considerada idonea, de modo que seja presumivel não commetter outra infracção

Ainda na mesma época, é editado o Decreto 17.943-A de 12 de outubro de 1927, que estabelece o regramento específico de assistência social do menor, que cuida de crianças abandonadas, menores expostos, destituição de poder familiar e tutela, além de menores infratores. A lei ainda estabelece juízo de competência exclusiva para tratar de assuntos que envolvam crianças e adolescentes.

O Estado se envolve cada vez mais no cuidado com as crianças e adolescentes, em duas frentes, o amparo daquelas que não possuem família, bem como na prevenção da delinquência.

Além disso, a assistência social a crianças e adolescentes se institucionaliza, por meio da criação de órgãos no Poder Executivo diretamente envolvidos no cuidado com os menores. Dentre eles o Serviço de Assistência a Menores (SAM) criado pelo Decreto-Lei 3.799/1941, que transformou o Instituto 7 de Setembro, instituição encarregada de abrigar crianças em situação de desamparo, em órgão vinculado ao Juizado de Menores do Ministério da Justiça.

$\mathrm{O}$ art. $2^{\circ}$ do citado Decreto-Lei estabelecia as seguintes atribuições ao SAM;

a) sistematizar e orientar os serviços de assistência a menores desvalidos e delinquentes, internados em estabelecimentos oficiais e particulares ;

b) proceder à investigação social e ao exame médico-psicopedagógico dos menores desvalidos e delinqüentes;

c) abrigar os menores, á disposição do Juízo de Menores do Distrito Federal;

d) recolher os menores em estabelecimentos adequados, afim de ministrar-lhes educação, instrução e tratamento sômato-psíquico, até o seu desligamento;

e) estudar as causas do abandono e da delinquência infantil para a orientação dos poderes públicos;

f) promover a publicação periódica dos resultados de pesquisas, estudos e estatísticas.

Inicialmente o SAM tinha caráter centralizador, como órgão do Governo Federal. A Portaria 125 do Ministério da Justiça e Negócios Interiores internalizou o SAM, criando inspetorias regionais em Belém, Fortaleza, Recife, Salvador, Niterói, São Paulo Belo Horizonte e Porto Alegre. Revela-se, portanto, nítida intenção do Estado se fazer presente nas diversas regiões brasileiras, para o cuidado com a infância.

O Código Penal de 1940 inova, mais uma vez, ao definir os menores de 18 anos como inimputáveis criminalmente. O Decreto-Lei n. 6.026/1943 veio, então, regulamentar a situação daqueles com menos de 18 anos que praticavam atos contrários à legislação penal. 
Nesta norma, a legislação já é significativamente mais branda do que a existente antes do Código Penal:

Art. $2^{\circ}$ São as seguintes as medidas aplicáveis aos menores de 14 a 18 anos: a) se os motivos e as circunstâncias do fato e as condições do menor não evidenciam periculosidade, o Juiz poderá deixá-lo com o pai ou responsável, confiá-lo a tutor ou a quem assuma a sua guarda, ou mandar interna-lo em estabelecimento de reeducação ou profissional e, a qualquer tempo, revogar ou modificar a decisão;

b) se os elementos referidos na alínea anterior evidenciam periculosidade o menor será internado em estabelecimento adequado, até que, mediante parecer do respectivo diretor ou do órgão administrativo competente e do Ministério Público, o Juiz declare a cessação da periculosidade.

Entretanto, durante o regime militar, a Lei 5.258/1967 voltou a estabelecer um regime mais duro contra os adolescentes em confronto com a lei. A norma retoma uma posição subjetiva para o magistrado, que poderá analisar a situação de abandono moral do jovem para impor-lhe medida de internação. Além disso, no caso da prática de atos previstos na lei penal como crimes punidos com reclusão, ao adolescente deveria ser aplicada medida de internação em estabelecimento próprio:

Art. $2^{\circ}$ Os menores de 18 anos e maiores de 14 , pela prática de fatos definidos como infrações penais, ficam sujeitos às seguintes medidas, sem prejuízo das referidas no artigo $1^{\circ}$ :

a) Se o menor pratica fato definido em lei como infração penal a que não seja cominada pena de reclusão e fôr moralmente abandonado, pervertido ou se achar em perigo de o ser, o Juiz poderá, tendo em conta os elementos mencionados no $\S 1^{\mathrm{o}}, 2^{\mathrm{a}}$ parte, dêste artigo:

1) interná-lo em estabelecimento apropriado para a sua reeducação, pelo menos por seis meses e até no máximo, atingir idade de 21 anos, provendo sôbre as condições da internação observado o disposto nos $\S \S 3^{\circ}, 4^{\circ}, 1^{\mathrm{a}}$ parte $8^{\circ}$ e $10^{\circ}$ dêste artigo.

2) entregá-lo à sua família ou a uma outra idônea, mediante as condições que determinar, ressalvada a internação se a medida se mostrar insuficiente.

b) Se o menor praticar fato definido em lei como infração penal a que seja cominada pena de reclusão, o Juiz mandará interná-lo em estabelecimento apropriado para a sua reeducação, pelo tempo e nas condições constantes dos parágrafos seguintes:

Ocorre que, em menos de um ano da publicação desta norma, o critério de periculosidade do adolescente voltou a ser considerado para fins de verificação da penalidade a ser aplicada, conforme texto da Lei n. 5.439, de 22 de maio de 1968. 
Então, em 1979 é editado o Código de Menores. A lei continua aplicável apenas para menores em situação de vulnerabilidade, de forma restritiva, estabelecendo quais crianças estariam abrangidas pelas normas que estabelece:

Art. $1^{\circ}$ Este Código dispõe sobre assistência, proteção e vigilância a menores:

I - até dezoito anos de idade, que se encontrem em situação irregular;

II - entre dezoito e vinte e um anos, nos casos expressos em lei.

Parágrafo único - As medidas de caráter preventivo aplicam-se a todo menor de dezoito anos, independentemente de sua situação.

Art. $2^{\circ}$ Para os efeitos deste Código, considera-se em situação irregular o menor:

I - privado de condições essenciais à sua subsistência, saúde e instrução obrigatória, ainda que eventualmente, em razão de:

a) falta, ação ou omissão dos pais ou responsável;

b) manifesta impossibilidade dos pais ou responsável para provê-las;

Il - vítima de maus tratos ou castigos imoderados impostos pelos pais ou responsável;

III - em perigo moral, devido a:

a) encontrar-se, de modo habitual, em ambiente contrário aos bons costumes;

b) exploração em atividade contrária aos bons costumes;

IV - privado de representação ou assistência legal, pela falta eventual dos pais ou responsável;

V - Com desvio de conduta, em virtude de grave inadaptação familiar ou comunitária;

VI - autor de infração penal

O Código de Menores passa a se preocupar mais intensamente com a colocação de crianças em lares substitutos e na estatização do cuidado com as crianças e adolescentes. Pode-se entender esta como uma das medidas iniciais de proteção da infância e juventude.

\section{DA PROTEÇÃO INTEGRAL}

Observe-se, que até este momento, não há qualquer tipo de proteção para a criança ou adolescente, como sujeitos de direito. O que a legislação pátria zela é para evitar que crianças e adolescentes sem família fiquem desamparadas, em situação de mendicância, gerando problemas sociais ainda mais sérios.

O reconhecimento da criança como sujeito de direitos somente veio a ser reconhecido pela legislação com a promulgação da Constituição da República de 1988.

Desde o anteprojeto apresentado, a proteção à infância e juventude, de maneira ampla, já foi considerada como direito fundamental de caráter social: 
Art. 342 - A ordem social tem por fim realizar a justiça social, com base nos seguintes princípios:

(...)

IX - proteção eficaz à infância, à adolescência e à velhice; (anteprojeto, p. 61)

Esta foi uma demanda de diversos setores da sociedade civil, na busca do reconhecimento de direitos da criança e do adolescente, não apenas quando em situação de vulnerabilidade, mas em todos os aspectos de sua vida civil. Este processo de reconhecimento de direitos, no Brasil, positivou-se com a inclusão no texto da Constituição de 1988 do reconhecimento da criança e do adolescente como sujeito de direitos, e tem seu ponto alto com a incorporação ao ordenamento brasileiro da Convenção sobre os Direitos da Criança, na ONU, e com a publicação do Estatuto da Criança e do Adolescente, Lei 8.069/1990.

O debate já estava instaurado no cenário internacional, como se verifica da promulgação da Convenção sobre os Direitos da Criança, e que foi precedida de outras discussões supranacionais.

O Pacto Internacional sobre Direitos Econômicos, Sociais e Culturais, internalizado no ordenamento brasileiro pelo Decreto n 591 - de 6 de julho de 1992, estabelece que "devese conceder à família, que é o elemento natural e fundamental da sociedade, as mais amplas proteção e assistência possíveis, especialmente para a sua constituição e enquanto ela for responsável pela criação e educação dos fillhos” (BRASIL 1992).

No mesmo sentido são as Regras Mínimas das Nações Unidas para a administração da Justiça, da Infância e da Juventude (Regras de Beijing), adotadas pela Assembleia Geral da ONU, em 29 de novembro de 1985.

O item 18.2 deste documento normativo estipula que "nenhum jovem será excluído, total ou parcialmente, da supervisão paterna, a não ser que as circunstâncias do caso tornemno necessário" (Assembleia Geral da ONU 1985), dando conta da mudança de perspectiva para considerar crianças e adolescentes como sujeitos de direito.

A norma citada, pois, explica a necessidade de proteção da criança e do adolescente dentro de uma perspectiva de proteção e não de encargo social. A regra supranacional impõe aos Estados signatários, pois, a criação de mecanismos para garantir o direito de permanecer sob a supervisão de seus pais, de modo a assegurar que sua dignidade será resguardada.

$\mathrm{Na}$ América Latina este foi um movimento muito característico e específico. Discutiu-se, com bastante intensidade a Convenção Internacional dos Direitos da Criança, tanto no cenário acadêmico, quanto junto à sociedade civil organizada, especialmente forte na 
década de 1980. Superou-se, pois, a doutrina da situação irregular, que vislumbrava a atuação do Poder Público tão somente dentro de um discurso assistencialista e de necessidade de controle social. (COSTA 2012).

No Brasil, o processo de redemocratização, e a crescente divulgação pela imprensa de situações de violência contra crianças e adolescentes, num quadro de retorno à liberdade de imprensa, justificou este debate. O "I Encontro Nacional de Meninos e Meninas de Rua", promovido em Brasília, em 1986, pode ser reconhecido como o marco inicial de discussão acerca da situação das crianças e adolescentes. Na ocasião, "foi possível constatar a organização de diversas entidades da sociedade civil, e em especial a "Pastoral do Menor", criada em 1979 por D. Paulo Evaristo Arns, arcebispo da cidade de São Paulo” (GRACIANI 1997, pp. 262-263).

Registre-se, por oportuno, que o Movimento Nacional dos Meninos e Meninas de Rua (MNMMR) e a Pastoral do Menor, da Igreja Católica tinham tamanha representatividade social que foram capazes de recolher mais de 1,5 milhões de assinaturas para fundamentar a emenda popular que conferiu a redação final ao art. 227 da Constituição da República, no qual consta a proteção integral à criança e ao adolescente (LONGO 2014).

No texto promulgado em 1988, a Constituição, além de incluir a infância como direito social, ainda, incluiu no art. 227 o dever do Estado, sociedade e família em zelar pela criança e o adolescente com absoluta prioridade.

Logo no início dos debates da Assembleia Nacional Constituinte, a Subcomissão da Família, do Menor e do Idoso já mostravam a preocupação de assegurar que crianças e adolescentes fossem objeto da proteção do Estado, dentro de sua família. E discutiu-se, especialmente, "Que proteção é essa, em que o Estado vai ter que se preparar e municiar para fornecer, ajudar a esses membros da família?” (Porto 21.04.1987, 28).

Os debates em relação à proteção da infância se concentraram em positivar, na nova Constituição, as normas já vigentes na Declaração Universal dos Direitos da Criança, de 20 de novembro de $1959^{4}$, cujo primeiro princípio é de proteção a todas as crianças, indistintamente:

\footnotetext{
4 O SR. CONSTITUINTE NELSON AGUIAR: - Sim, não deveria. Então, pensamos numa fórmula que incorporasse todos os direitos enunciados na Declaração Universal dos Direitos da Criança. Por isso, na proposta anterior que fiz, constam direitos que foram amputados aqui nesta proposta e peço vênia a V. Ex ${ }^{a}$ para acolhe-la na emenda que estou encaminhando: "...assegurados os seguintes direitos: à vida, à profissionalização e à convivência familiar e comunitária." Acho que são direitos fundamentais, mesmo porque, nos demais preceitos, não tratamos desses direitos. Vejam bem, colocamos ali "à vida, à saúde e alimentação", e paramos aí. Na minha proposta tínhamos, tentado ser fiel ao princípio da Declaração Universal dos Direitos da Criança, acrescentando "à educação, ao lazer, à habitação, à profissionalização e à prop elaboração desta Constituição, mas a dívida maior da sociedade brasileira é com a criança, hoje. Não temos como fugir disso e ela está nos cobrando de arma na mão e nós, sem termos como pagar a dívida, estamos pagando prendendo-as nas diversas instituições que temos e ainda estamos elaborando formas de leis, de juizados e coisas desse tipo para nos inocentarmos do maior crime que se pratica contra a humanidade, em termos de Brasil, que é o abandono da infância. Pois bem, acho que temos essa responsabilidade Histórica, e ainda que percamos por excesso, não pequemos por omissão. Queira apenas fazer referência a esse ponto. (p. 184)
} 


\title{
Princípio I
}

- A criança desfrutará de todos os direitos enunciados nesta Declaração. Estes direitos serão outorgados a todas as crianças, sem qualquer exceção, distinção ou discriminação por motivos de raça, cor, sexo, idioma, religião, opiniões políticas ou de outra natureza, nacionalidade ou origem social, posição econômica, nascimento ou outra condição, seja inerente à própria criança ou à sua família.

Neste propósito, foram ouvidas entidades representativas de inúmeros segmentos sociais e se pode notar uma viragem do discurso em relação à legislação então existente. As discussões no âmbito da Subcomissão se voltavam para a proteção da criança e do adolescente, como pessoas em desenvolvimento, e a preservação da infância em sua essencialidade.

Confira-se:

\begin{abstract}
Não posso aceitar que em, em hipótese nenhuma, uma criança ajude na manutenção da família. A criança tem de brincar e estudar, e o Estado tem que se preocupar com o salário do adulto. Se o adulto não tem dinheiro para sustentar a família, vai colocar seu filho menor que deve estar preparado para amanhã ser até Presidente da República embora tenha nascido numa classe pobre.

Se ele ficar trabalhando aos 7 anos, não dá tempo para estudar, não dá tempo para se preparar convenientemente para uma escalada social e econômica.

Nossos filhos, se não os obrigarmos a estudar, vão ficar na rua brincando.

Dizer que o trabalho dignifica o homem, ora, a criança não é um adulto, e não posso aceitar que seja tratada como tal. É uma criança. A sua formação moral e a sua formação intelectual está ainda por vir. (Bizotto s.d., 119)

A outra [proposta] seria: as crianças e os jovens terão a especial proteção do Estado que tem que lhes assegurar o desenvolvimento sadio, estimulando- lhes o sentimento de solidariedade humana, de amor e liberdade. (Mariano s.d., 120)
\end{abstract}

Fica claro, pois, o cuidado que a Assembleia Nacional Constituinte teve ao reconhecer a criança e o adolescente como sujeitos de direitos, para assegurar lhes proteção, não apenas em situação de desamparo, mas em todas as perspectivas de sua vida em situação de desenvolvimento. Além disso, a Constituição inova o ordenamento jurídico ao repartir a responsabilidade por esta proteção prioritária entre o Estado, a sociedade e a família.

Vale destacar a grande mudança que a nova Constituição causou para a proteção da criança e do adolescente, visto que deixam de ser objeto da atenção do Estado apenas quando destituídos de suas famílias ou em situação de delinquência. A partir do reconhecimento constante do art. 227 da Constituição, passam as ser objetos de políticas públicas específicas, observando a responsabilidade do Estado de zelar pela integridade de toda criança e adolescente, com máxima prioridade.

Assim, se abre espaço para uma série de readequações do Direito à sociedade brasileira em transformação, viabilizando a modificação desde o reconhecimento da criança e 
do adolescente, como sujeitos de direitos, como dito, até o reconhecimento que o próprio conceito de família se modifica sensivelmente.

Antes em uma situação de desamparo, e objeto de uma política assistencialista e de necessidade de controle social, a criança e o adolescente que estão fora de seu contexto familiar, agora, merecem proteção no texto constitucional como sujeitos de direitos.

Ao Poder Público se imbuiu o dever de zelar para que toda a criança e o adolescente possa se desenvolver no âmbito familiar, ainda que se trate de família substituta na ausência ou impossibilidade da família biológica acolhê-los.

A regra é explícita no texto do art. 226 do texto constitucional brasileiro, que declara ser a família a base da sociedade e merecer integral proteção do Estado. O art. 227, como antes discutido, determina que a infância deve ser protegida pela família, pela sociedade e pelo Estado, em todas as suas circunstâncias. O texto do art. 227 determina a necessidade de proteção absoluta, garantindo “o direito à vida, à saúde, à alimentação, à educação, ao lazer, à profissionalização, à cultura, à dignidade, ao respeito, à liberdade e à convivência familiar e comunitária, além de colocá-los a salvo de toda forma de negligência, discriminação, exploração, violência, crueldade e opressão" (BRASIL 1988).

A proteção da infância e as relações familiares, pois, já não são objeto exclusivo do ambiente privado das relações interpessoais. Não se pode mais falar de poder familiar restrito aos muros de proteção do ambiente doméstico. A proteção da infância deve ser lida no contexto do Direito Público. Cite-se a conceituação de Silvio Rodrigues, sobre o poder familiar, para quem "é um munus público imposto pelo Estado aos pais, a fim de que zelem pelo futuro dos filhos. É do interesse do Estado assegurar a proteção das gerações novas, pois ela constitui matéria-prima da sociedade futura" (RODRIGUES 1979, p. 151)

Desta forma, a positivação dos direitos da criança e do adolescente, na nova Constituição gerou, além do reconhecimento destes como sujeitos de direitos, a obrigação do Estado em pensar em políticas públicas específicas para a infância, de modo a assegurar a proteção integral. E, ao mesmo tempo, autoriza a cobrança perante o Poder Judiciário da integral atenção e proteção aos direitos sociais agora positivados, consequentemente, lhe instrumentalizam de forma a viabilizar que tenha condições de assegurar o fornecimento do direito, observando que se trata de situação onde haverá que observar a formação de vínculos de afetividade, ou seja, assegurar que os laços em formação serão resistentes o suficiente para formar uma família. 
As inovações do texto constitucional, pois, criam uma série de posições jurídicas novas para crianças e adolescentes. A partir da promulgação da Constituição, nasce para estas pessoas em desenvolvimento uma série de compromissos do Estado para com elas.

Ao Estado cabe, portanto, o dever de satisfazer, respeitar e promover o rol de direitos que agora passam a figurar como Direitos Fundamentais no texto constitucional. Observe-se, contudo, que há neste ponto, uma série de direitos que devem ser concretizados ao longo do tempo, observando-se a reserva do que é politicamente adequado e oportuno (NOVAIS 2010). Sem embargo, contudo, de que eventuais limitações orçamentárias não se prestam a justificar o não atendimento de políticas públicas definidas como fundamentais na Constituição, porque “encontra insuperável limitação na garantia constitucional do mínimo existencial, que representa, no contexto de nosso ordenamento positivo, emanação direta do postulado da essencial dignidade da pessoa humana" (STF ARE 639337 2011);

Vale destacar, inicialmente, que o conceito de família contido na Constituição de 1988 é contemporâneo com a realidade da sociedade brasileira. A família é vista como um ente "descentralizado, democrático, igualitário e desmatrimonializado. O escopo precípuo da família passa a ser a solidariedade social e demais condições necessárias ao aperfeiçoamento e progresso humano, regido o núcleo familiar pelo afeto, como mola propulsora" (FARIA 2004, p. 56). Isso porque "a pessoa humana, o desenvolvimento de sua personalidade, o elemento finalístico da proteção estatal, para cuja realização devem convergir todas as normas de direito positivo, em particular aquelas que disciplinam o direito de família, regulando as relações mais íntimas e intensas do indivíduo no social" (TEPEDINO 1999, p. 216).

Como a família é um ente que se fundamenta nas relações de afeto, a proteção constitucional que se confere é direcionada para a entidade na qual quaisquer pessoas estejam reunidas com a intenção de manter relações de afetividade ${ }^{56}$.

\footnotetext{
5 A decisão do Supremo Tribunal Federal, na qual se reconheceu a união estável entre casais homossexuais, consagrando a proteção da família, indistintamente da origem de sua formação. (Cf. ADPF 132, Relator(a): Min. AYRES BRITTO, Tribunal Pleno, julgado em 05/05/2011, DJe-198 DIVULG 13-10-2011 PUBLIC 14-10-2011 EMENT VOL-02607-01 PP-00001)

6 Pode-se citar, ainda, a enquete realizada pela Câmara dos Deputados ( http://www2.camara.leg.br/agenciaapp/votarEnquete/enquete/101CE64E-8EC3-436C-BB4A-457EBC94DF4E), que perguntou se "Você concorda com a definição de família como núcleo formado a partir da união entre homem e mulher, prevista no projeto que cria o Estatuto da Família?", no âmbito das discussões do Projeto de Lei 6583/13, que cria o Estatuto da Família. Ainda que não se possa atribuir conteúdo científico ao resultado, a enquete recebeu 4.397.060 votos, revelando a atualidade e importância da discussão acerca do conceito de família. Naquele caso 50,19\% dos que votaram entenderam que o conceito de família não é formado pela união entre homem e mulher.
} 
Esta é a proteção que o art. 227, § 6 , da Constituição (BRASIL 1988), de reconhecer direitos indistintamente aos filhos, havidos ou não da relação do casamento, ou por adoção. Até porque é direito fundamental da criança e do adolescente a convivência familiar. Busca-se analisar, aqui, em que condições o Poder Público exerce o seu dever de proteção integral à criança e ao adolescente, especialmente no cuidado para que se desenvolvam em um ambiente familiar.

A Lei 8.069/90, que regulamenta aquele dispositivo constitucional, estabelece uma rede de proteção à infância e juventude, formada por entes de todas as esferas governamentais, com funções definidas dentro das suas respectivas competências, criando os instrumentos necessários para a efetivação dos direitos fundamentais instituídos em 1988, para assegurar a proteção integral à infância e à juventude.

\section{CONSIDERAÇÕES FINAIS}

As crianças e adolescentes, apenas em 1988, com a promulgação da Constituição, passaram a ser considerados sujeitos de direitos. O texto constitucional promulgado passou a conter um rol exclusivo de direitos fundamentais voltado para esta parcela da população, exigindo a proteção do Estado brasileiro com absoluta prioridade para crianças e adolescentes, cuja responsabilidade é solidária entre a família, a sociedade e o Estado.

Esta não foi uma decisão unilateral da Assembleia Nacional Constituinte, mas o reflexo de um processo histórico que envolveu significativa parcela da sociedade civil, em benefício das crianças e adolescentes. Modificou-se o paradigma de proteção e, portanto, a postura dos aplicadores do direito no momento de atender a uma expectativa dessa parcela da população, com menos de 18 anos de idade.

Até porque, a mera inclusão de direitos no texto da Constituição não é por si só suficiente, sem que, simultaneamente, sejam assegurem os meios necessários e eficientes para concretizá-los.

Especial atenção, contudo, deve ser dada a crianças e adolescentes que enfrentam situação de risco dentro de sua família ou não mais a possuem, visto que estão sob a proteção do próprio Estado. Para estas, cabe ao Estado suprir as funções que seriam dividas também com a família e com a sociedade, já que, diante da inexistência de um núcleo familiar capaz de dar-lhes a proteção devida, a proteção constitucional como sujeito de direitos lhes 
assegura, na condição de sujeitos de direitos, esta proteção específica por parte do Estado. Observa-se que, age o Estado, aqui, como corresponsável pelos cuidados necessários ao desenvolvimento das crianças e adolescentes e não como um agente que irá resolver um problema social - como eram vistas as crianças nas décadas de 1950 e 1960. Crianças e adolescentes têm, portanto, seus direitos resguardados em sua integridade, como pessoas cuja dignidade deve ser preservada e para quem devem ser direcionados esforços para a preservação de seus direitos fundamentais.

Para estas crianças e adolescentes, foi necessário constitituir uma rede de apoio composta por diversos entes estatais, pertencentes aos três Poderes Políticos, bem como da iniciativa privada, de modo a assegurar a efetivação de todos os direitos e garantias constitucionais positiviados, como reflexo da modificação do paradigma social.

\section{REFERÊNCIAS}

Assembleia Geral da ONU. “Resolução 40/33 .” Regras de Beijing. 1985.

Bezerra, PARECER DA RELATORA Deputada Teté. "COMISSÃO ESPECIAL DESTINADA A APRECIAR E PROFERIR PARECER AO PROJETO DE LEI No 6.222, DE 2005, DO SENADO FEDERAL, QUE "DÁ NOVA REDAÇÃO AO § 2o DO ART. 46 E AO CAPUT DO ART. 52 DA LEI No 8.069, DE 13 DE JULHO DE 1990 - ESTATUTO DA CRIANÇA E DO ADOLESCENTE,."

Bizotto, Margarida. “10a reunião da Subcomissão.” 119.

BOSCHI, Caio. “O assistencialismo na Capitania do Ouro.” Revista de História, jan-jun ed.

BRASIL. “Constituição.” Constituição da República Federativa do Brasil. 1988. ."Decreto 591 ." Decreto 591 . 1992.

“"Estatuto da Criança e do Adolescente.” Lei 8069. 1990.

“Lei 8.242.” Lei 8.242. 1991.

CELLARD, André. "A análise documental." In: A pesquisa qualitativa - enfoques epistemológicos e metodológicos, por Jean POUPART. Rio de Janeiro: Vozes, 2008.

CNJ. http://www.cnj.jus.br/sistemas/infancia-e-juventude.

Cadastro Nacional de Adoção. http://www.cnj.jus.br/programas-de-aa-z/infancia-e- juventude/cadastro-nacional-de-adocao-cna. 
(acesso em Novembro de 2014).

CONANDA. "Orientações Técnicas: Serviços de Acolhimento para Crianças e Adolescentes." 2009. http://www.mds.gov.br/assistenciasocial/secretaria-nacional-de-assistencia-socialsnas/cadernos/orientacoes-tecnicas-servicos-de-acolhimento-para-criancas-e-adolescentestipo-de-publicacao-caderno/orientacoes-tecnicas-servicos-de-acolhimento-para-criancas.

FACHIN, Luiz Edson. Elementos críticos do direito de família: curso de direito civil. Rio de Janeiro: Renovar, 1999.

FARIA, Cristiano Chaves de. "A família da pós-modernidade: em busca da dignidade perdida da pessoa humana." evista de Direito Privado, julho de 2004.

FAUSTO, Boris. História do Brasil. São Paulo: Editora da Universidade de São Paulo: Fundação para o Desenvolvimento da Educação,, 2001.

LONGO, Isis S. "To be adolescent and child in the brazilian society: passed and present of the history of youthful rights." 13 de nov de 2014. http://www.proceedings.scielo.br/scielo.php? script=sci_arttext\&pid=MSC0000000092010000100013\&lng=en\&nrm=abn >.

MARCÍlLIO, Maria Luiza. História Social da Criança Abandonada. São Paulo: Editora Hucitec, 1998.

Mariano, Roberto. “10ª reunião da Subcomissão.” 120.

Porto, Comba Marques. “ATA DA 4ª REUNIÃO ORDINÁRIA.” 21.04.1987.

Portugal. “Tit. 88: Dos Juízes dos Orfãos Título LXXXVIII." Ordenações Filipinas. Vol. Livro 1.

POUPAT, Jean. A pesquisa qualitativa: Enfoques epistemológicos e metodológicos. São Paulo: Vozes, 2008.

RE 410715 AgR. RE 410715 AgR (STF).

RODRIGES, Silvio. Direito de Família. São Paulo: Saraiva, 1979.

RODRIGUES, Flávia Sílvia, e Ana Laura Godinho LIMA. "INSTITUIÇÕES DE ASSISTÊNCIA À INFÂNCIA NO BRASIL NAS DÉCADAS.” novembro de 2014. http://sbhe.org.br/novo/congressos/cbhe2/pdfs/Tema7/7113.pdf.

TEPEDINO, Gustavo. Temas de direito civil. Rio de Janeiro: Renovar, 1999.

TRINDADE, Judite Maria Barboza. "O abandono de crianças ou a negação do óbvio." Revista Brasileira de História, 1999, setembro ed. 